\title{
THE A NNALS
}

A N D

\section{MAGAZINE OF NATURAL HISTORY.}

\author{
[FIFTH SERIES.]
}

No. 60. DECEMBER 1882.

\section{XLIV.-Mimicry between Butterflies of Protected Genera. By Raphael Meldola.}

IN 1879 the late Charles Darwin called my attention to a paper by Dr. Fritz Müller, in 'Kosmos'*, in which this naturalist attempted to explain the outstanding cases of mimicry, viz. those cases in which both the genera concerned are protected by distastefulness, by an extended application of the principle of natural selection, thus bringing the whole of these interesting phenomena under the action of Darwinian factors. I was at the time so much struck by the ingenuity of the reasoning employed, that $I$ published a translation of the paper in the "Proceedings of the Entomological Society of London' $(1879$, p. xx). The same author has recently published a second paper on this subject, an account of which has already been given in 'Nature' $\dagger$ by Mr. A. R. Wallace, who not only states Fritz Müller's case with his usual force and clearness, but gives the additional weight of his own authority to the proposed extension of the meaning of the term " mimicry." It is not necessary here to recapitulate Fritz Müller's arguments ; I need only remind entomologists that he shows how it is advantageous for one species to

" "Ituna and Thyridia; a remarkable case of Minicry in ButterHies," ' Kosmos,' May 1879, p. 100.

† " Remarkable Cases of acquired Resemblance among Butterflies," ' Kosmos,' 1881; 'Nature,' vol. xxvi. p. 86.

Ann.\& Mag. N. Hist. Ser. 5. Vol.x. 
resemble another which is more abundant in individuals, although both may possess distasteful qualities. The chief factor concerned in bringing about this resemblance is the inexperience of young birds and other insectivorous foes, which necessitates the sacrifice of a certain number of distasteful individuals before they are recognized as inedible. In the papers published in 'Kosmos' no direct evidence of such inexperience is adduced; and in a subsequent number of ' Nature'* $\mathrm{Mr}$. W. L. Distant, whose special knowledge of Lepidoptera gives considerable weight to his opinion, objected to the theory advanced by Fritz Müller and accepted by Mr. Wallace, on the ground that a knowledge of eatable and uneatable insects is hereditary in birds, and that no individuals of protected species would be sacrificed to the inexperience of young birds as required by the theory. In his recently published part of the 'Rhopalocera Malayana' (part ii. p. 33), Mr. Distant adduces some further arguments against the new view of mimicry; and I have only delayed entering into the discussion up to the present time in order to give Fritz Müller the opportunity of defending his views. Having just received a letter from this eminent naturalist, I will now venture to consider the validity of the objections referred to.

The experiment of the late $\mathrm{Mr}$. Spalding, quoted by $\mathrm{Mr}$. Distant in support of his objection, will be found, on close analysis, not to have any direct bearing on the class of cases under consideration. A young turkey bred in confinement displays fear when for the first time in its life it comes across a bee; and similarly chickens " gave evidence of instinctive fear of these sting-bearing insects." Now the alarm displayed by a young bird at the sight of a bee has no analogy whatever with the inexperience of a young bird as regards nauseous butterflies, as I will immediately attempt to show.

The swallowing of a stinging-insect like a bee would probably be attended by very unpleasant if not serious consequences in the case of a young bird; and it is not in the least surprising therefore that a dread of such insects should in this instance have become hereditary. But I cannot see how we are warranted in reasoning from this experiment that a knowledge of uneatable butterflies should also have become hereditary in all young insectivorous birds. No very serious result would arise from a young bird pecking at and killing such butterfies; and amidst the countless swarms of insects in the tropics there must be a vast choice of food offered, so that the knowledge of nauseous species at first sight is not a matter of life and death, and there is thus no reason why this * Vol. xxvi. p. 105 . 
knowledge should have become unerringly fixed by heredity in all young birds. In the case of the very bird in question, there is, in fact, direct evidence that no such instinctive knowledge exists. Mr. Stainton relates (Proc. Ent. Soc. 1866, p. xlv) that he was in the habit of killing moths that had been attracted by light by the fumes of burning sulphur, and on one occasion, on throwing the useless specimens to a brood of young turkeys, "amongst a number of $A$. exclamationis, there was one specimen of Spilosoma menthastri; and though not one of the young turkeys rejected a single $A$. exclamationis, they each, in succession, took up the S. menthastri and put it down again, and it was left, conspicuous as it was, on the ground." In the case of insectivorous foes other than birds there is also evidence upon record that even adult lizards and frogs do not know some nauseous insects till they have actually seized them, as has been shown by the experiments of A. G. Butler with the caterpillar of Abraxas grossulariata and the imago of Zygcena filipendula (Trans. Ent. Soc. 1869, p. 27).

Passing from these old and now well-known experiments, I will give an extract from Dr. Fritz Müller's last letter :-

"It appears to me always worth while to discuss thoroughly the question whether birds and other butterfly-eaters know eatable and uneatable species through instinct à priori, or whether they have to learn this through individual experience. I hope to be able to do this shortly in 'Kosmos.' In the case of birds, I have as yet no direct proof; but in insects, and especially in bees, my brother Hermann Müller and $\mathbf{I}$ have repeatedly observed that they neither know instinctively the flowers which serve to provide them with honey or pollen nor the way in which their booty is best to be obtained. Today, for the first time, a new illustration has been furnished by Trigona ruficrus in visiting a Cypella which offers easily accessible honey and pollen, and which the majority of these bees nevertheless could not at first find. Thus, by analogy, the same would occur in birds with respect to eatable insects as in insects with respect to flowers yielding nutriment."

As one piece of evidence bearing upon this subject, Dr. Müller encloses in his letter a specimen of a Heliconius which had apparently been seized, when at rest, by some bird, as there is a notched piece bitten out of the two fore wings ; and I have in my possession another specimen of Heliconius which is similarly notched on both hind wings.

There is one other argument which may be adduced from psychology in favour of the proposed extension of the theory of mimicry. It is admitted by psychologists that there.is a 
strict analogy between the development of bodily structure and of psychological characters, both in individuals and in species. The law of embryonic development formulated by Häckel as the "fundamental biogenetic law," teaches that the individual, in the course of its development from the egg (ontogeny), recapitulates with more or less disguise and abbreviation the phases through which its ancestors have passed in the course of the development of the race (phylngeny). Ancient characters are retained to a late stage of life only in cases where they are of direct service to the species, as, for example, in the retention of a subdorsal line by certain ocellated sphinx-caterpillars*. Why should not this same law be extended to instinct? If instinct is habit acquired during the former experience of the race, and accumulated and fixed by heredity, we may fairly expect that an animal, in the course of its mental development (psychological ontogeny), would pass through the stages of inexperience which were gone through by its ancestors in the course of their evolution. Only where an "instinct" was of vital importance to the young would it become fixed upon the early stages of growth by the law of inheritance at corresponding periods. The instinctive fear of bees shown by Mr. Spalding's turkey may be a case in point. But if, as I believe, the knowledge of a nasty butterfly is not a matter of vital importance, there is no reason why young birds should know such species antecedent to experience. This part of the discussion may, I think, be very well left at this stage pending the appearance of some satisfactory experiments with young tropical insectivorous birds and inedible butterflies.

The arguments advanced by Mr. Distant in discussing the question of mimicry in his 'Rhopalocera Malayana' are based on a consideration of the case of Euplaea Distanti and $E$. Bremeri, and may be thus stated :-

The male Euploea Distanti closely resembles E. Bremeri, but is distinguished by the possession of a "pseudo scent-gland." To continue in the author's own words:- "It is at least a question whether the term 'mimicry' should be used here, both species belonging (as I consider, and most entomologists till recently considered) to the same genus. All the species of Euploea with which we are acquainted, and as Mr. Wallace has informed us, have, with the remaining Danaince of the Old-World tropics, the 'same protective odour.' In this case, if we adopt the explanation of mimicry for the resemblance of these two species, we must presumably consider $E$. Distanti

* Weismann's 'Studies in the Theory of Descent,' Engl. edit. Appendix, p. 529. 
as the mimicked species, as it pozsesses a pseudo scent-gland, which may reasonably be considered as adding to its protective or uneatable character, and which is absent in E. Bremeri. We thus have the 'mimicking' very much more abundant than the 'mimicked' species, which is contrary to the usually observed phenomena, though Fritz Müller has recorded some similar exceptions as occurring in Brazil, and the same observer has also endeavoured to show that there is an advantage in two nauseous species resembling each other, as occurs between two American species, both of which belong to genera which are protected from birds and other enemies by distasteful qualities. Such propositions are, of course, at present hypothetical, and are at least supplementary to the carefully observed facts on which Mr. Bates originally disclosed and argued the admirable doctrine of ' mimicry,' which accounted for the strange external resemblances, long known to entomologists, which existed between insects belonging to distinct genera, families, and even orders, between which there was no real affinity" (Rhop. Malay. p. 33).

It seems to me, on carefully considering the foregoing extract, that the author has mixed up two very distinct things as being "at present hypothetical," viz. (1) the statement that a mimicking species is sometimes more abundant than its model, and (2) the demonstration that there would be an advantage in one distasteful species resembling another distasteful and more abundant species. The former is a simple record of observation and involves no hypothesis whatever. Thus in the case of such mimetic pairs as Mechanitis lysim$n i a$ and its imitating Leptalis, and Papilio nephalion and its mimicking Euterpe tereas, there can be no doubt as to which is the model; and Fritz Müller has observed that the models are, in these instances, " hardly more common" or are much rarer than the mimics. This was at least the case in the part of Brazil where he made this observation*.

The second "proposition" is hypothetical only to the extent of our not having any direct observations upon the inexperience of young insectivorous birds and other enemies. If we grant, as appears to me most probable, and as Fritz Müller and Mr. Wallace have admitted, that a certain number of individuals of distasteful species have to be sacrificed to inexperience, it follows mathematically that there would be a great gain in one distasteful species resembling another which exceeded it in numbers. If therefore, in the case of Euploa Distanti and E. Bremeri, we accept Mr. Distant's position, and with him "adopt the explanation of mimicry for the resem.

* Ann. \& Mag. Nat. Hist., Feb. 1878, p. 157. 
blance of these two species," we can only admit the mimetic theory in Fritz Müller's sense, and the question as to which species is the model and which the mimic need not cause any anxiety. In such cases the raver species would always be adapted in external characters to the commoner one. The inference that $E$. Distanti is the model is therefore erroneons from the new point of view; and, in spite of its "pseudo scentgland," I believe that we must regard it as the mimic of $E$. Bremeri.

To bring the argument home to entomologists, I will once more venture to state the case numerically, with special reference to the species under discussion, using Fritz Müller's own figures for this purpose. Let us suppose that at the time when $E$. Distanti and $E$. Bremeri were quite distinct there existed in a certain area during one season 10,000 individuals of the latter and 2000 of the former. If, say, 1200 individuals of a nauseous species are necessary for the education of young birds, this number would in each case be sacrificed, and the total number of butterflies lost would be 2400 . But if the two species were so much alike that their foes could not distinguish them, then we should have what, from a mimetic point of view would be, as regards birds \&c., only one species, consisting of 12,000 individuals, of which 1200 have to be sacrificed. Now the loss would in this case fall upon the species in the ratio of their numbers, viz. $5: 1$; so that $E$. $B$ remeri would lose 1000 and $E$. Distanti 200 individuals.

In the former state of affairs (before the resemblance) each species would have lost 1200 ; now $E$. Distanti gains 1000 individuals by its resemblance and $E$. Bremeri only 200. The total number of individuals with which we started was 10,000 of $E$. Bremeri and 2000 of $E$. Distanti; so that the last species gains $\frac{1080}{2000}$ or $\frac{1}{2}$, and the first species 120000 or only $\frac{1}{50}$ of its whole number. The advantage in favour of the rarer $E$. Distanti, conferred upon it by its being mistaken for $E$. Bremeri, would thus be twenty-five times as great as the advantage which the commoner $E$. Bremeri derives from resembling $E$. Distanti. Surely in such a case the question as to which is the model does not admit of a doubt.

This extension of the theory of mimicry, as far as I am able to see, makes no greater claim upon the credulity of naturalists than the older and more restricted view which made it essential that the mode] should always belong to a protected group, and the mimic to a family devoid of distasteful qualities. The factors concerned are in both cases the same-variation and natural selection; and the term "mimicry" is as applicable to one class of cases as to the other. Mr. Distant, how- 
ever, not only refuses to admit the Batesian theory in the case of two protected species (because they happen to be nearly allied or even in the same genus), but would restrict the original theory within such narrow limits that no philosophical entomologist can possibly accept his interpretation. Thus he states:- "The original argument that butterflies which were known by observation to be uneatable or protected were mimicked in appearance by different butterflies which did not possess distasteful qualities for the sake of a similar protection, does not warrant the conclusion that because two or more buttertlies or other insects (of or not of the same genus) resemble each other, therefore, without observation of the fact, it is proved that one must be protected or uneatable, and the other or others are mimickers" (Rhop. Malay. pp. 33, 34).

If, in accordance with this statement, we are to confine the term " mimicry" to those cases only in which the model is " known by observation" to be uneatable, it may be fairly asked how far we know that such imitated groups as $H_{e}$ liconius, Euploea, Danais, Acrcea, \&c. are distasteful. But very few direct observations have, as far as $\mathrm{I}$ am aware, been made even upon these groups which are generally admitted to be the objects of imitation; and I certainly know of no systematic experiments conducted with these models and insectivorous foes. Thus the resemblance of Diadema misippus \& to Danais plexippus may be called "mimicry," because Danais is "known by observation" to be a protected genus. But are the resemblances between such genera as Apatura and Athyma, Laogona and Neptis, \&c. not to be considered as " mimicry" simply because we do not know with certainty which form to call the model? If we refuse to admit the theory of mimicry in such cases as the latter, we should leave unexplained a very large number of most exact imitations between very distinct genera-a retrograde step which few scientific entomologists will be disposed to take.

In the case of the two Euploeas upon which Mr. Distant bases his objections, the fact of their being near blood-relations seems to be the great stumbling-block which prevents him from admitting the mimetic explanation. But it is somewhat surprising that an author, whose work is so far in advance of all other works of the kind in the knowledge displayed in the philosophical portions of his subject, should have overlooked or should have failed to mention the fact that Mr. Bates in his original memoir admits mimicry between nearly related (and distasteful) groups. $\mathrm{He}$ says:- "Not only, however, are Heliconidæ the objects selected for imitation, some of them are themselves the imitators; in other 


\section{On Mimicry between Butterfies of Protected Genera.}

words, they counterfeit each other, and this to a considerable extent. Species belonging to distinct genera have been confounded owing to their being almost identical in colours and markings; in fact many of them can scarcely be distinguished, except by their generic characters. It is a most strange circumstance connected with this family that its two sections or subfamilies have been mingled together by all authors, owing to the very close resemblance of many of their species. Analogies between the two subfamilies have been mistaken for affinities. It is sometimes difficult to understand in these cases which is the imitator and which the imitated. . . ." ('Trans. Linn. Soc. vol. xxiii. p. 507).

This extract from the writings of the founder of the theory of mimicry proves to my mind conclusively that Mr. Bates had himself observed the resemblance between nearly related and protected groups; and Mr. Distant's strictures upon the theory must, in my belief, give way. He admits that true mimicry may occur between different sections of the same genus, as has been shown to be the case in Papilio by Mr. Wallace, and more recently by Mr. Wood-Mason. But here, again, I would ask how Mr. Distant knows "by observation" that one section is inedible? The arguments based on the presence or absence of a scent-gland must be used with the greatest caution in determining which group serves as the model. This appears most forcibly from the inconsistencies which Mr. Distant has himself brought to light when making use of this character as a criterion. Thus, he states that if we admit the theory of mimicry in the case of Euploea Distanti and $E$. Bremeri, "we must presumably consider" the former to be the model, because of its pseudo scent-gland. Further on he continues :- "But in the genus Euploea we have at present no knowledge of non-nauseous or non-protected species, and therefore the probability of the species 'mimicked' being E. Distanti, because of its possession of a pseudo scent-gland, and hence presumably protective advantage, is somewhat negatived by the fact that some Euploces without these glands are mimicked by other and very divergent species, as, notably, E. midamus by Papilio paradoxa and P. anigma. The possession of these glands does not therefore appear necessary for distastefulness. ..." \&c. (loc. cit. p. 33). Such facts as those mentioned appear to me to be conclusive against the said glands being of any use as a protection. Indeed there are many dull groups, both of butterflies and moths, which we have no reason to regard as being distasteful, and of which the males are provided with large scent-glands or tufts, e. g. Mycalesis, Erebus, \&c. The position which 
Mr. Distant takes at the outset of this argument is in fact fallacious. There is not the least warrant for the supposition that scent-glands or tufts have any thing to do with distastefulness. The acrid juices of distasteful butterflies are not generally emitted from any particular organ, but permeate all the tissues of the body. The fact that such organs exist in one sex only is strongly suggestive, if not demonstrative, of the view that they are secondary sexual characters; and as such they are regarded by Dr. Fritz Müller, who has systematically investigated these structures, and has in many cases actually detected the odour emitted, which is often of a pleasant character *.

I have entered at some length into this discussion, because I am persuaded that the extension of the theory of mimicry proposed by Fritz Müller marks a great advance in our views on this subject, which is so interesting as having been the first to which the Iarwinian Theory of Evolution was applied with such success by Mr. Bates. Not only are we now in possession of a consistent theory which enables us to dispense with mysterious and "unknown local causes," but other groups of facts hitherto incomprehensible are capable of explanation. Thus the prevalence of one type of marking and colouring throughout immense numbers of species in protected groups, such as the tawny species of Danais, the barred Heliconias, the blueblack Euploeas, and the fulvous Acroeas, is perfectly intelligible in the light of the new hypothesis. While the unknown factors of species-transformation have in these cases caused divergence in certain characters, other characters, viz. superficial colouring and marking, have been approximated or prevented from diverging by the action of natural selection, every facility having been afforded for the action of this agency by virtue of the near blood-relationship of the species concerned. When discussing the origin of mimicry, Mr. Darwin long ago suggested that it might have commenced at a time when the species were more nearly related in marking and colouring $t$.

\section{XLV.-Black-Sea Mollusca. By J. Gwyn Jefrreys, LL.D., F.R.S.}

Mx friend Admiral Spratt has, with his usual kindness, given me a few small shells, which he dredged in the Black Sea while surveying in 1855. None of them, except Mytilus

- Jen. Zeit. vol. xi. p. 99 : Trans. Eut. Soc. 1878, p. 211.

† Origin of Species, 6th ed. p. 377. 